\title{
Investigating Pitting Corrosion of Stainless Steel and Aluminium Using Scanning Vibrating Electrode Techniques and Electrochemical Noise Measurement
}

\author{
Chinwuba Victor Ossia ${ }^{1}$, Charles Ugochukwu Orji ${ }^{2}$ \\ ${ }^{1}$ Offshore Technology Institute, Graduate School of Engineering \& Technology, University of Port Harcourt, Port Harcourt, Nigeria \\ ${ }^{2}$ Offshore \& Hydrodynamics Group, School of Marine Science \& Technology, Newcastle University, Newcastle-Upon-Tyne, United \\ Kingdom
}

\section{Email address: \\ ossiacv@otiuniport.org (C. V. Ossia)}

\section{To cite this article:}

Chinwuba Victor Ossia, Charles Ugochukwu Orji. Investigating Pitting Corrosion of Stainless Steel and Aluminium Using Scanning Vibrating Electrode Techniques and Electrochemical Noise Measurement. International Journal of Mechanical Engineering and Applications. Vol. 4, No. 2, 2016, pp. 71-80. doi: 10.11648/j.ijmea.20160402.16

Received: April 13,2016; Accepted: April 22, 2016; Published: May 7, 2016

\begin{abstract}
In this study, the susceptibility of aluminium (Al) and steel $\mathrm{SS} 304$ to pitting corrosion in $\mathrm{FeCl}_{3}$ and $\mathrm{NaCl}$ solutions with varying $\mathrm{pH}$ values were investigated using electrochemical noise (ECN) measurement and Scanning Vibrating Electrode Technique (SVET). Preliminary surface drop test of SS304 in $\mathrm{FeCl}_{3}$ solution and total immersion test of $\mathrm{Al}$ in $\mathrm{NaCl}$ solution indicated higher pitting of samples at scratches simulated by scribe. Total immersion test on both SS304 and Al indicated that protecting a sample with epoxy-resin mold does not completely eliminate crevice attack. ECN tests results showed that Al suffered severe time-variant corrosion in $\mathrm{FeCl}_{3}$ solution unlike SS304. The results of SVET tests conducted after 24h immersion indicated that the early pits captured on $\mathrm{Al}$ samples were more intense than the later ones. Higher corrosion rates were obtained for samples in $\mathrm{NaCl}$ solution of $\mathrm{pH} 2.89$ compared to $\mathrm{pH} 7.21$, indicating that pitting increased with acidity. SVET maps obtained corroborated Scanning Electron Microscopy (SEM) images of the sampled surfaces. However, though SVET was unable to capture pitting of SS304 in the solutions, SEM image revealed pitting activity on the sample in $\mathrm{FeCl}_{3}$ solution.
\end{abstract}

Keywords: Scanning Vibrating Electrode Technique (SVET), Electrochemical Noise (ECN), Coefficient of Variation (CoV)

\section{Introduction}

Due to massive socio-economic loss and the attendant safety problems, corrosion has been extensively studied in an attempt to minimize its hazardous effects and thus possibly prevent its occurrence [1]. The corrosion engineer is thus embattled with the task of eliminating this economic wastage. It is evident that the earth crust is made up of $70 \%$ of marine environment, besides; the atmosphere sustains dense mass of water vapour and dissolved chemicals which are products of global industrialization. Most engineering materials are exposed to this harsh environment which tends to be corrosive [2]. Sea water contains a higher concentration of dissolved salts (predominantly $\mathrm{NaCl}$ ) than any other natural liquid, except body fluid, salt lake and saline springs. Thus, it can be considered to be responsible for a vast percentage of the world corrosion wastage. Hence, many expensive equipment like the drill ships, ocean liners, offshore rigs, automobiles, underground/underwater gas and oil pipelines suffer massive attacks from this corrosion phenomenon and as such put the lives of crew onboard at risk [3].

To underscore the corrosion phenomenon, in 1975 a comprehensive study of metallic corrosion was carried out by the National Bureau of Standards (NBS) and Battelle memorial institute in response to a congressional directive and a published figure of seventy billion dollars (\$70billion) was reported as the loss for metallic corrosion [4], an enormous amount of capital capable of salvaging the dwindling economy of some third world nations.

Metals are the most widely used engineering materials, of which steel and aluminum are among the top ranking in utility. Corrosion which is generally defined as the 
degradation of a metal in reaction with a corrosive environment [1], [2], [3], does not spare these metals. There are basically different kinds of corrosion attacks, of which stainless steel and aluminum are greatly attacked by localised forms of corrosion (crevice and pitting corrosion) [1], [5]. These forms give no noticeable indication and many function as crack initiation sites which may propagate into material failure when subjected to mechanical working conditions. To investigate the susceptibility of these materials to pitting corrosion in an environment, weight loss index has been used, and this involves the resulting difference in weight of materials after exposure of the metal to the environment under service conditions for specific time periods. This procedure is slow, uneconomical and a poor representation for evaluating rates for metals in most slow corroding environment. Besides, very small localised mass losses are scarcely and inaccurately captured and quantified. Hence the need for the development of techniques which could capture and quantify these localised activity, and subsequently used to predict future events (accelerated testing).

Pitting can be a very destructive form of corrosion in engineering structures particularly if it causes equipment perforations, although minor pitting void of causing any noticeable perforation is most times tolerated in engineering practice for economic reasons. But were economic index cannot be matched to safety, need for exposing pits even at nanoscales then arise. In confirmation, corrosion pits were identified as crack origins on a test on aluminum in $3.5 \% \mathrm{wt}$ $\mathrm{NaCl}$ solution (model sea water) [6]. It is not surprising that there has been an enormous research effort towards developing techniques to handle this problem of quickly assessing and predicting the susceptibility of a metal to pitting.

Some of these techniques include atomic force microscopy (AFM) [7], [8], scanning electrochemical microscopy (SECM) [9], scanning tunneling microscope (STM) [10], electrochemical noise (ECN) [11], [12], Electrochemical Impedance spectroscopy (EIS) [13], and Scanning reference electrode technique (SRET) [15]. The Scanning vibrating electrode technique (SVET) [16], adopted in this study belong to this SRET group, all of which function under the principle of their ability to pick up little changes in electrochemical activity within a localised pit and amplifying it [18], [19]. This study examines the susceptibility of two metals, stainless steel and Al, to pitting using SVET and the ECN box measurements in chloride environments to mimic seawater conditions.

\section{Materials and Methods}

\subsection{Materials}

\subsubsection{Stainless Steel (SS304) and Aluminium Samples}

Small blocks of aluminium (Al) (99.95\% purity) and stainless steel (SS304) were cut to $(15.4$ x 15.4$)$ mm crosssection. Electrical connectivity of samples was made by lead soldering a conductive copper wire to the rear side of the sample. For firm positioning of sample during SVET test, samples were embedded in an inert epoxy resin mould (Figure 1(a)), made from a mixture of 5:1 wt (epoxy resin: resin hardener) ratio, which was hardened for $20-24 \mathrm{~h}$ before removal. This mould is to protect sample edges from possible crevice corrosion attack when in contact with the electrolyte during experiments.

The surface of the sample is treated to a fine finish by grinding on silicon carbide paper in the sequence of 240,600 , 1200, 2400 Grit size and polishing using diamond compound slurry in the sequence of $6 \mu$ to $1 \mu$. This keeps the surface homogeneous and eliminates contours which could damage the fragile platinum probe tip, hence giving wrong / false output signals. It reduces occlusions that may pose as sources of pseudo localised corrosion.

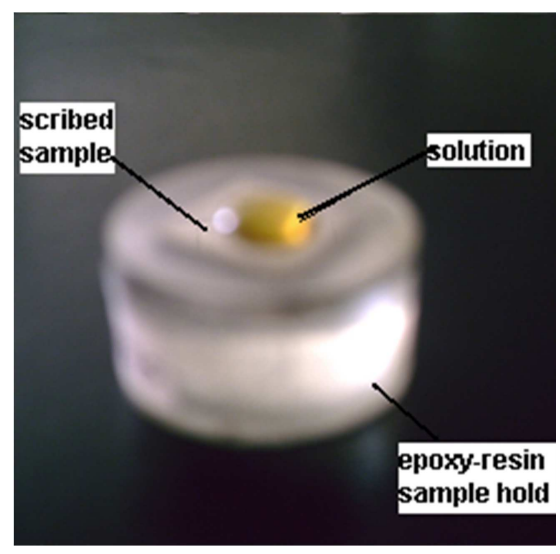

(a)

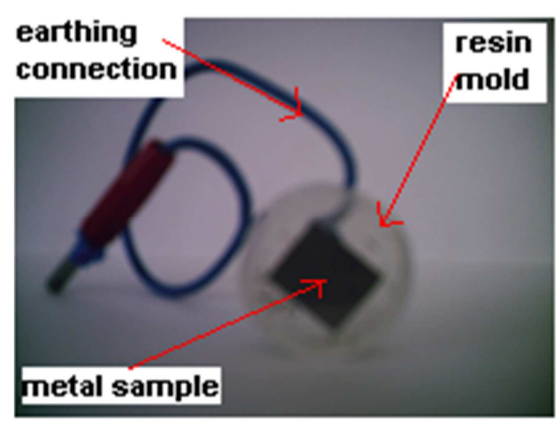

(b)

Figure 1. (a) Prepared Sample embedded in epoxy-resin mould; (b) Drop of $10 \% \mathrm{FeCl}_{3}$ on sample of finely scribed SS304.

\subsubsection{Electrolyte Solution}

$3 \% \mathrm{NaCl}$ solution was prepared by dissolving $30 \mathrm{~g}$ of laboratory sodium chloride salt in $1000 \mathrm{ml}$ of laboratory tap water introducing small drops of $\mathrm{HCl}$ (molar concentration unknown) into the solution to obtain the desired $\mathrm{pH}$-value.

$10 \% \mathrm{FeCl}_{3} \cdot 6 \mathrm{H}_{2} \mathrm{O}\left(\equiv 6 \% \mathrm{FeCl}_{3}\right)$ was prepared by dissolving $10 \mathrm{~g}$ of hydrated $\mathrm{FeCl}_{3} \cdot 6 \mathrm{H}_{2} \mathrm{O}$ in $90 \mathrm{ml}$ of lab water. Hydrolysis of $6 \% \mathrm{FeCl}_{3}$ produces an acidic solution of $1.2-1.3 \mathrm{pH}$ value. The $\mathrm{Fe}^{3+}$ acts as the oxidizer by reduction to $\mathrm{Fe}^{2+}$ and the $\mathrm{Cl}^{-}$is the pitting agent. A combination of this two qualities results in the aggressive environment for testing the resistance for the metals towards pitting [6]. 


\subsection{Methods}

\subsubsection{Total Immersion Tests}

- A 3-face Al sample, prepared to give three different surface profiles (plain. scribed and indented), was immersed in $3 \% \mathrm{NaCl}$ and observed for $24 \mathrm{~h}$.

- Unscribed samples of SS304 and Al were totally immersed in $10 \% \mathrm{FeCl}_{3} \cdot 6 \mathrm{H}_{2} \mathrm{O}$ for $48 \mathrm{~h}$.

- Similarly, scribed samples (moppet scribing) of same samples were immersed in $10 \% \mathrm{FeCl}_{3} \cdot 6 \mathrm{H}_{2} \mathrm{O}(\equiv 6 \%$ $\mathrm{FeCl}_{3}$ ) and $3 \% \mathrm{NaCl}$.

\subsubsection{Surface Drop Tests}

- Two samples of SS304, (one with scribe, and one without scribe), were tested for corrosion by dropping $10 \% \mathrm{FeCl}_{3} \cdot 6 \mathrm{H}_{2} \mathrm{O}$ on the surface and left for $1 \mathrm{~h}$ as in Figure 1(b).

- Also, similar experiments were done using $\mathrm{Al}$ sample in $\mathrm{FeCl}_{3}$ and $\mathrm{NaCl}$ solution.

\subsubsection{ECN Measurement}

The Potentiostat (Gill AC, ACM Instruments, Cumbria$U K)$ with ancilliary equipment were connected as in Figure 2 and used for ECN current and potential-time measurements.

Scribed samples of $\mathrm{Al}$ and SS304, with edges or interface between epoxy and metal covered using an epoxy/beeswax mixed to $3: 1$ wt ratio, were connected to the workingelectrode WE1 terminal of the Noise box (ACM Instruments, Cumbria-UK) from the rear part of the sample. Measurements were carried out against a non-corroding reference electrode, at rates of $0.2 \mathrm{~s}$ per point for 3000 or 2000 sampling points, giving sampling periods of $600 \mathrm{~s}$ or 400 s, respectively. Solutions used include $10 \% \mathrm{FeCl}_{3}$ and $3 \%$ $\mathrm{NaCl}$ with $\mathrm{pH}$ values $7.21,6.21,5.01,3.12$ and 2.35 . Readings were taken at $0 \mathrm{~h}, 1 \mathrm{~h}, 3 \mathrm{~h}, 6 \mathrm{~h}, 24 \mathrm{~h}, 27 \mathrm{~h}, 48 \mathrm{~h}$ and $51 \mathrm{~h}$ intervals after immersion.

\subsubsection{SVET Measurement}

\section{(a) SVET Point-In-Space (PIS) Calibration}

The Scanning Vibrating Electrode Technique (SVET) apparatus (SVP100, Uniscan Instruments, Buxton-UK) was connected-up with its ancillary equipment as shown in Figure 2 for the SVET experimental-runs.

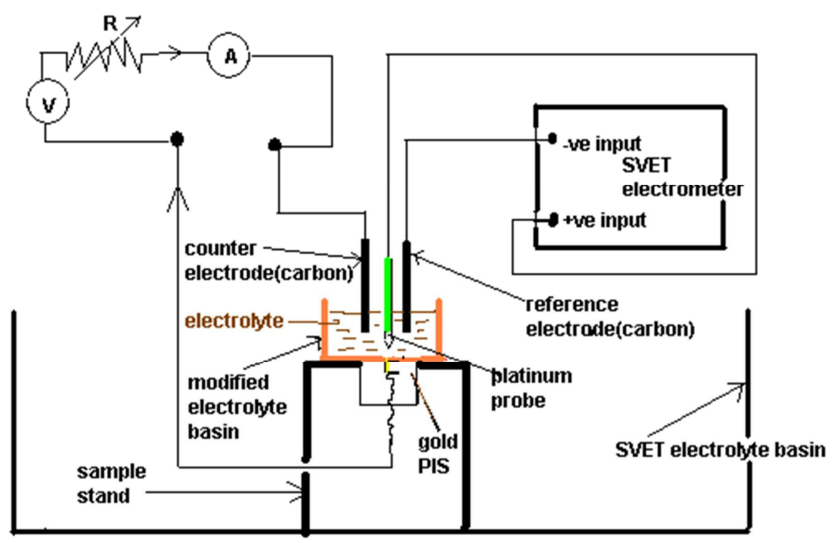

(a)

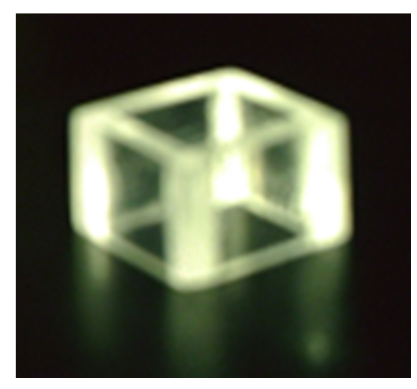

(b)

Figure 2. (a) Schematic diagram of modified SVET-up for PIS calibration, (b) Perspex box.

- 10 line scans were run, at scan velocity of $200 \mu \mathrm{m} / \mathrm{s}$, probe-specimen distance of about $90 \mu \mathrm{m}$, probe vibration amplitude of $35 \mu \mathrm{m}$, with a passage of current of $27 \mathrm{~mA}$ over a gold PIS of area of $0.03146 \mathrm{~mm}^{2}(\approx$ $\varnothing 0.2 \mathrm{~mm})$. A carbon electrode was used as the reference electrode and the set-up shown in Figure 2 and illustrated schematically in Figure $2 \mathrm{a}$ was used as a substitute to the bigger basin through the use of smaller Perspex box (Figure 2b). This experiment was repeated for the solutions of $10 \% \mathrm{FeCl}_{3} \cdot 6 \mathrm{H}_{2} \mathrm{O}-\mathrm{pH} 1.30,3 \%$ $\mathrm{NaCl}$ at $\mathrm{pH}$ 7.21, 2.41 and 2.91.

- To test solution/beeswax contamination, some portion of the prepared epoxy-beeswax, was soaked in a beaker containing aqueous $\mathrm{HCl}$ with a concentration of (33$40 \%) \mathrm{HCl} /(60-67 \%) \mathrm{H}_{2} \mathrm{O}$, and left for days.

\section{(b) SVET Scans}

To accommodate the Perspex box introduced, the set-up shown in Figure 3 was used for the experiment. Samples were earthed through the electrometer box in accordance with Original Equipment Manufacturers (OEM) provision for free corrosion test-earthed sample [20].

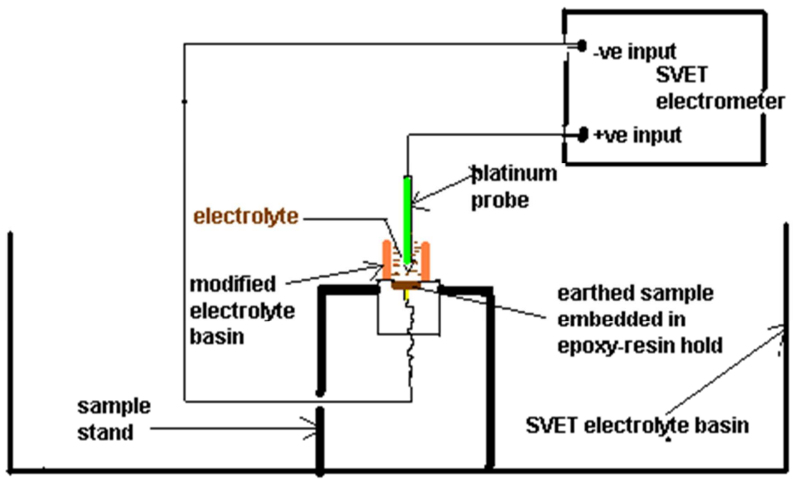

Figure 3. Schematic diagram of modified SVET-UP for free corrosion test (earthed sample).

- Earthed scribed sample of SS304 in 3\% $\mathrm{NaCl}$ with pH 2.89 was line scanned over 3-days, at probe distance $90 \mu \mathrm{m}$, probe vibration amplitude $35 \mu \mathrm{m}$, scan velocity $200 \mu \mathrm{m} / \mathrm{s}$.

- Another line scan with similar specification as above was performed for SS304 in $10 \% \mathrm{FeCl}_{3} \cdot 6 \mathrm{H}_{2} \mathrm{O}$. Area scan was also carried out in the same solution.

- Two line scans, were carried out for scribed Al 
samples at $\mathrm{pH} 2.89$ and 7.21 , at $0 \mathrm{~h}$ and $24 \mathrm{~h}$ after immersion. The scan specifications used are the same for step-(a) above.

\section{Results and Discussions}

\subsection{Total Immersion}

The results of the immersion tests are shown in the Figure 4.

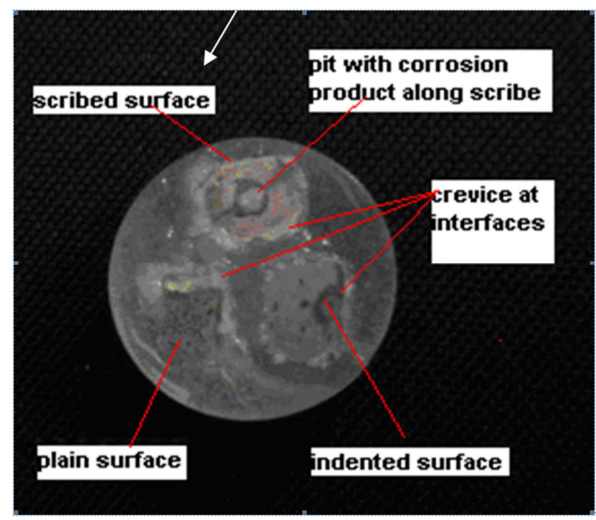

(a)

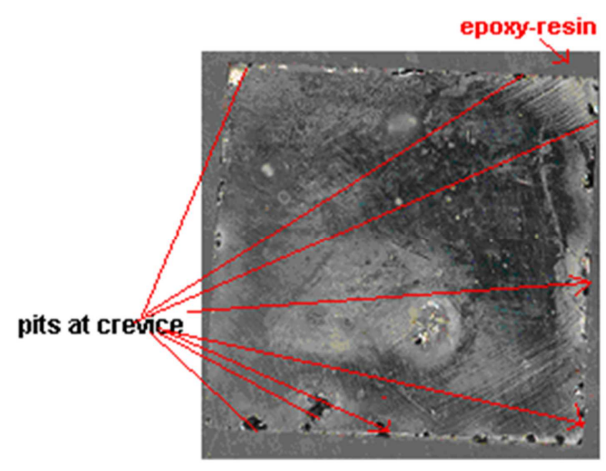

(b)

Figure 4. (a) Digital camera picture of a 3-faced sample of pure Al immersed in 3\% NaCl after 24h; and (b) SEM Image of SS304 immersed in $10 \% \mathrm{FeCl}_{3}$ for $48 \mathrm{~h}$.

The $\mathrm{SS} 304$ immersed in $\mathrm{FeCl}_{3}$ precipitated with heavy pitting at the crevices. The $\mathrm{Al}$ sample immersed in $10 \% \mathrm{FeCl}_{3}$ precipitated with the evolution of $\mathrm{H}_{2}$ gas and general uniform corrosion were visually observed, no pits were found on scanning. White formations suspected to be corrosion products of $\mathrm{Al}_{2} \mathrm{O}_{3}$ were formed both at sample-epoxy interface indicating some form of crevice attack on all three profiles (Figure 4) and also at the near central location for the scribed surface. Bubbles were also observed but more with $\mathrm{FeCl}_{3}$ solution. $\mathrm{SS} 304$ did not show any form of activity even after several weeks of immersion in $\mathrm{NaCl}$ solution.

Artificial scratches are used to simulate the mechanical or chemical breakdown of the passive oxide film, exposing the metal to the corrodent. The picture of Figure $4 \mathrm{a}$ shows the visible formation of pits on the scribed surface as compared with the other profiles, despite the crevice attack at the sample-epoxy interface. Similar experiment depicted in
Figure 5 showed the heavy concentration of pits along the scribe as compared to the other parts of the metal surface. The change in colour from brown to green observed during this test was simply as a result of the reduction of ferric ions $\left(\mathrm{Fe}^{+3}\right)$ to ferrous ions $\left(\mathrm{Fe}^{+2}\right)$, indicating that there was actually corrosion which lead to the pits being formed. The embedded sample of Figure $4 \mathrm{~b}$ indicates the formation of crevice attack on sample, which tends to cathodically protect the sample surface from possible pitting. This condition is not very favorable for the pitting experiment; as such this informed the need to protect the interface again with an epoxybeeswax mix.

\subsection{Surface Drop Test}

On dropping the $\mathrm{FeCl}_{3}$ solution on the scribed SS304 and Al samples, a few visible gas bubbles evolved from the $\mathrm{Al}$ sample after $300 \mathrm{~s}$ and continued thereafter, no pits were found on microscopic observation and scanning using the optical scanner. The SS304 sample exhibited some localised formations or pits concentrated along the artificial scratch or scribe as shown in Figure 8 after $0.5 \mathrm{~h}$. In both cases there was a change of colour from brown $\mathrm{FeCl}_{3}$ to green, which indicates the reduction of $\mathrm{Fe}_{3}$ into $\mathrm{Fe}_{2}$, due to corrosion or metal oxidation [5].

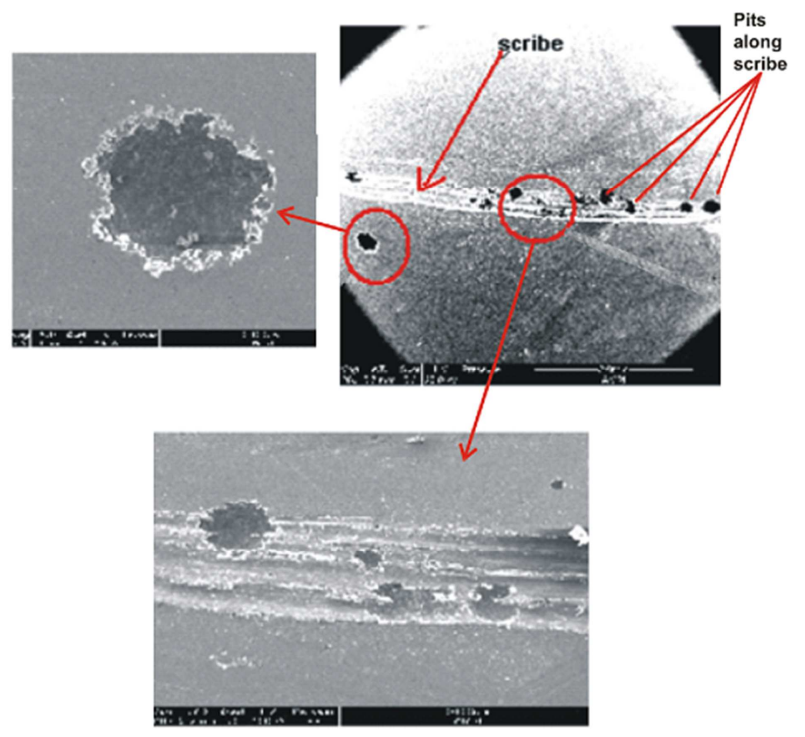

Figure 5. SEM image of SS304 sample showing pit formation along scribe after drop test with $\mathrm{FeCl}_{3}$ for 0.5 h immersion.

Scanning the drop on metal surface would have been a better way of getting SVET to pick pits along the scribe, but there exists a limitation, in the sense that the second probe tip is not in communication with the bulk solution as it is fitted above the main platinum tip, to sample the $\mathrm{pH}$ of the bulk solution [20]. This led to the use of the smaller Perspex box (Figure 2b) of volume $3 \mathrm{~cm}^{3}$ compared to 4000 $\mathrm{cm}^{3}$ of SVET basin. Besides, the economy of size, the box can also accommodate very acidic electrolytes which evolve unhealthy and dangerous fumes. Communication of the second probe tip was not a limitation for the 
modification as can be seen from Figure 2 and Figure 3.

\subsection{Electrochemical Noise (ECN) Tests}

\subsubsection{Current Density - Time Plot}

Since noise is random, an algebraic expression which defines the amplitude-time dependence of a particular source is impossible; and this means that noise is a nondeterministic process [21]. Fluctuations in corrosion potential are random; hence ECN are classified as nondeterministic and thus analyzed in terms of statistics and probability rather than algebraic equation. The results of the electrochemical current measurements for the different sample/solution combination are displayed as sample graphs in Figures 6, 7.

\section{Current density -time plot for SS304 in 10\% $\mathrm{FeCl} 3 . \mathrm{H} 2 \mathrm{O}$}

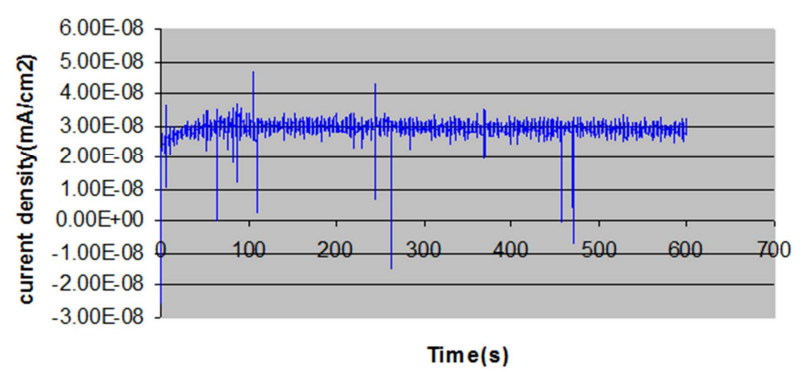

Figure 6. Current-time record for SS304 in $10 \% \mathrm{FeCl}_{3} .6 \mathrm{H}_{2} \mathrm{O}$ immediately after immersion.

Current density -time plot for $\mathrm{SS} 304$ in 10\% $\mathrm{FeCl} 3 . \mathrm{H} 2 \mathrm{O}$

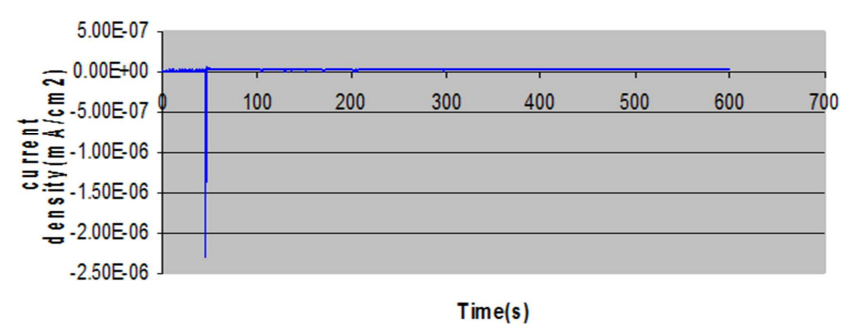

Figure 7. Current-time record for $\mathrm{SS} 304$ in $10 \% \mathrm{FeCl}_{3} \cdot 6 \mathrm{H}_{2} \mathrm{O} 24 \mathrm{~h}$ after immersion.

\subsubsection{Statistical Evaluation}

The statistical parameters of the current transients such as, Mean, standard deviation, Kurtosis k, and Skewness sK were evaluated based on the analysis tool pack add-in package in excel platform. From the results of the descriptive statistics of the current transients by ECN measurements of SS304 in $10 \% \mathrm{FeCl}_{3} .6 \mathrm{H}_{2} \mathrm{O}$ from $0-51 \mathrm{~h}$ immersion time, the following were observed:

- A steady decline in mean $\mu$ and variance $\sigma^{2}$ within 0 24h of immersion;

- Erratic standard deviation $\sigma$, Kurtosis K and Skewness sK within 0 - 24h of immersion;

- $\mathrm{CoV}$, and standard deviation $\sigma$ declined within $0-3 \mathrm{~h}$ immersion before a steady rise.

- From the results of the descriptive statistics of the current transients by ECN measurements of $\mathrm{Al}$ in $10 \%$
$\mathrm{FeCl}_{3} \cdot 6 \mathrm{H}_{2} \mathrm{O}$ from $0-51 \mathrm{~h}$ immersion time, the following were observed:

- CoV, Standard deviation $\sigma$ and Kurtosis $\mathrm{K}$ increased within 0 - 3h before decreasing;

- Skewness sK increased within 0-6h before decreasing, but;

- Mean $\mu$ was observed to be erratic.

From the $\mathrm{K}$ values obtained the dominant corrosion mechanism for $\mathrm{Al}$ in $10 \% \mathrm{FeCl}_{3} \cdot 6 \mathrm{H}_{2} \mathrm{O}$ were the intergranular corrosion $(\mathrm{K}>6)$ for time $\mathrm{t}<51 \mathrm{~h}$ immersion and general / uniform corrosion $(\mathrm{K}<6)$ after time $\mathrm{t} \geq 51 \mathrm{~h}$ immersion. However, for $\mathrm{SS} 304$ in $10 \% \mathrm{FeCl}_{3} \cdot 6 \mathrm{H}_{2} \mathrm{O}$ the dominant mechanism is intergranular $(\mathrm{K}>6)$. This corroborates the work of Cappeln et. al [22] who performed ECN measurements on AISI347, 10CrMo910, 15Mo3, and $\mathrm{X} 20 \mathrm{CrMoV} 121$ steels in molten $\mathrm{NaCl}-\mathrm{K}_{2} \mathrm{SO}_{4}$ at $630^{\circ} \mathrm{C}$. Different types of current noise were identified for pitting, intergranular and peeling corrosion. The corrosion mechanism was the so-called active corrosion (that is, the corrosion proceeds with no passivation due to the influence of $\mathrm{Cl}$ ), characterized by the formation of volatile metal chlorides as a primary corrosion product. An empirical separation of general and intergranular corrosion using kurtosis $\mathrm{K}$ was done. It was found that average $\mathrm{k}>6$ indicated intergranular corrosion and average $\mathrm{k}<6$ indicated general corrosion. The response time for localized corrosion detection in in-plant monitoring was approximately $90 \mathrm{~min}$ on this basis.

\subsubsection{Change in Coefficient of Variation (CoV) with pH-Values for SS304 and Al in 3\% NaCl Solution}

Table 1. CoV for SS304 and Al in 3\% NaCl solution at various pH values.

\begin{tabular}{|c|c|c|c|c|c|}
\hline \multicolumn{6}{|c|}{$\mathrm{SS304}$ in $3 \% \mathrm{NaCl}$ solution } \\
\hline \multirow{3}{*}{ Time (h) } & \multicolumn{5}{|c|}{$\mathrm{pH}$ of bulk solution } \\
\hline & 7.21 & 6.21 & 5.01 & 3.12 & 2.35 \\
\hline & \multicolumn{5}{|c|}{ Coefficient of variation $(\mathrm{CoV})$} \\
\hline 0 & 3.7278 & -1.6809 & 8.8435 & 2.8988 & 2.5192 \\
\hline 3 & 3.3761 & 0.1566 & 2.1654 & 1.2303 & 0.4913 \\
\hline 6 & 2.0800 & 0.1352 & 0.6432 & 1.0260 & 0.8979 \\
\hline 24 & 1.7849 & -1.0158 & 0.0923 & 0.2417 & 0.84596 \\
\hline 27 & -0.8557 & -0.2045 & 2.7301 & 6.9464 & 0.1838 \\
\hline \multicolumn{6}{|c|}{$\mathrm{Al}$ in $3 \% \mathrm{NaCl}$ solution } \\
\hline & \multicolumn{5}{|c|}{$\mathrm{pH}$ of bulk solution } \\
\hline \multirow[t]{2}{*}{ Time (h) } & 7.21 & 6.21 & 5.01 & 3.12 & 2.35 \\
\hline & \multicolumn{5}{|c|}{ Coefficient of variation $(\mathrm{CoV})$} \\
\hline 0 & -12.3020 & 7.0471 & 10.8339 & 1.0124 & 3.9322 \\
\hline 3 & -6.2100 & -2.0082 & 3.2116 & 3.4187 & 0.4901 \\
\hline 6 & 4.7811 & 0.1336 & 0.0751 & 0.4217 & 0.2268 \\
\hline 24 & 0.2046 & 0.1309 & 0.3146 & 0.1332 & 4.9236 \\
\hline
\end{tabular}

Evaluation of $\mathrm{CoV}$ variation with time at different $\mathrm{pH}$ values of the bulk solution shown above indicate a steady decline in $\mathrm{CoV}$ with immersion time for $\mathrm{pH}$-values of 7.21 and 5.01 for both $\mathrm{SS} 304$ and $\mathrm{Al}$ in $3 \% \mathrm{NaCl}$.

There was poor pitting characteristics of SS304 in pH 7.21 and $\mathrm{pH}$ 5.01. The pitting characteristics was fairly good at $\mathrm{pH}$ 6.21 during the early stages of immersion, although the physical observation of the current time records indicate that these transients are small compared to those of $\mathrm{FeCl}_{3}$ which indicating a more corrosive environment for pitting. After 
about $24 \mathrm{~h}$ immersion, records show that better pitting of SS304 occurred at pH 3.09 followed by 5.01 which was indicated by the sharp rise in the $\mathrm{CoV}$ values as a first and simple evaluation. Those at $\mathrm{pH} 6.21$ and 2.35 are fairly equal.

Similar observation were made for $\mathrm{Al}$ in $3 \% \mathrm{NaCl}$ solution, at $\mathrm{pH} 7.21$ where sharp rise in $\mathrm{CoV}$ in the first $6 \mathrm{~h}$ was observed, followed by sudden decline while that of $\mathrm{pH} 3.12$ and 2.35 showed some fine consistency after $24 \mathrm{~h}$ immersion.

Based on this deductions from the ECN test, it became necessary to carry out the SVET test on $3 \% \mathrm{NaCl}$ at $\mathrm{pH} 3.12$, 2.89 and 7.21 (neutral solution).

\subsection{SVET Test}

\subsubsection{Point-in-Space (PIS) Calibration Test}

The line scan maps obtained from the PIS calibration tests are shown in Figure 8, a scan of 1 in 10 line scans per solution.

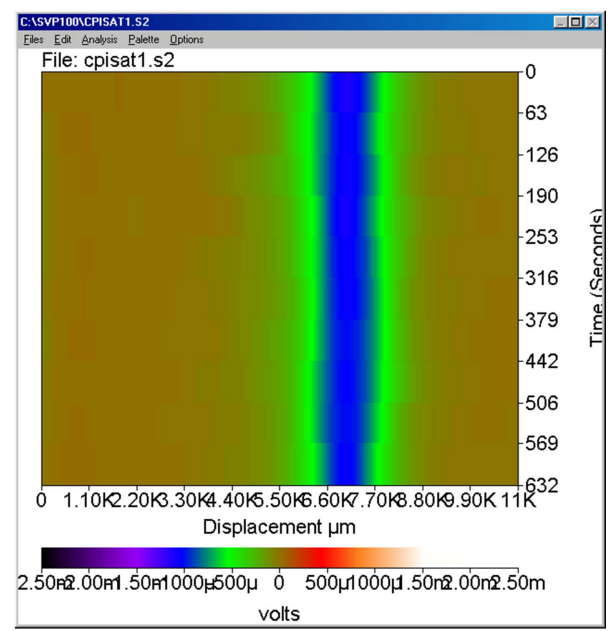

(a)

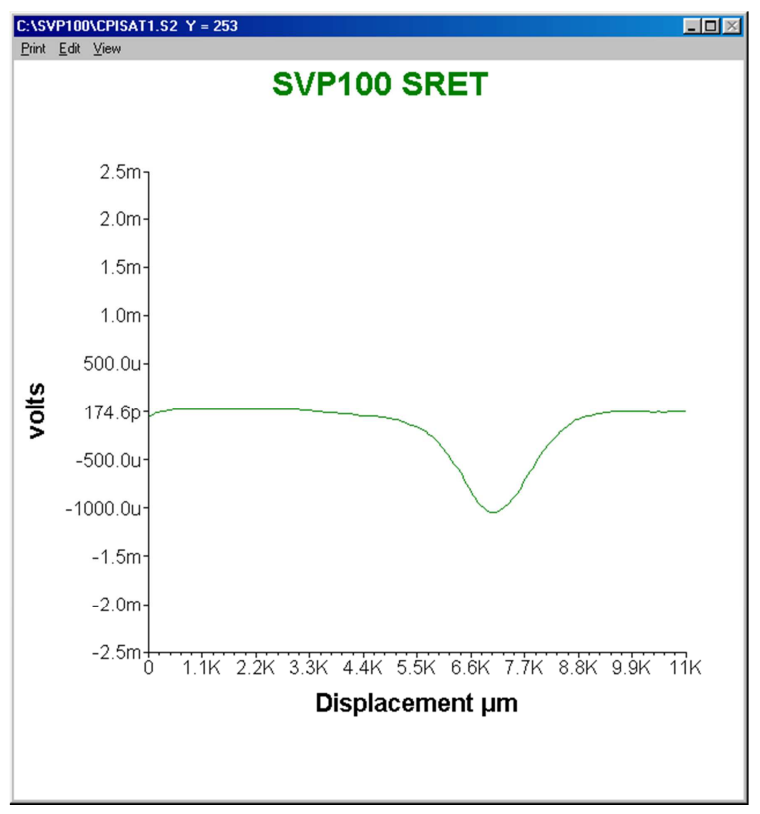

(b)

Figure 8. (a) Map showing 10 line scans for PIS calibration in $10 \% \mathrm{FeCl}_{3}$ solution; (b) Probe voltage signal versus displacement for a line scan from (a).
The values of the potential drop or probe peak signal as extracted from the line maps which are used for computation of the calibration factor $(\mathrm{CF})$ for the different electrolytes. An initial probe reading before sudden drop $=174.6^{*} 10^{-9} \mathrm{~V}$, applied current $=0.025 \mathrm{~mA}=25 \mu \mathrm{A}$ and applied current density $=79.46598856 \mathrm{~mA} / \mathrm{cm}^{2}$ were utilized to obtain the $\mathrm{CF}$ in accordance with OEM recommendation $\left(0-150 \mathrm{~mA} / \mathrm{cm}^{2}\right)$ within which a linear relationship exist between the measured probe output and the local current density [9]. The CF for different solutions includes:

- Solution $\mathrm{A}\left(10 \% \mathrm{FeCl}_{3} . \mathrm{H}_{2} \mathrm{O}\right.$ at $\left.\mathrm{pH} 1.30\right), 10$ line scan Average $\mathrm{E}_{\text {rpis }}--1.049 \mathrm{mV}, \mathrm{E}_{\text {eff }}-1.049 \mathrm{mV}$; CF $75727.719953 \mathrm{mAcm}^{2} / \mathrm{V}$;

- Solution B (3\% NaCl at pH 7.21), 10 line scan Average $\mathrm{E}_{\mathrm{rpis}}--1.784 \mathrm{mV}, \quad \mathrm{E}_{\text {eff }}-1.784 \mathrm{mV} ; \quad \mathrm{CF}$ $44531.868684 \mathrm{mAcm}^{2} / \mathrm{V}$;

- Solution $\mathrm{C}(3 \% \mathrm{NaCl}$ at $\mathrm{pH} 2.91), 10$ line scan Average $\mathrm{E}_{\mathrm{rpis}}--1.286 \mathrm{mV}, \quad \mathrm{E}_{\mathrm{eff}}-1.286 \mathrm{mV} ; \quad \mathrm{CF}$ $61765.550600 \mathrm{mAcm}^{2} / \mathrm{V}$;

- Solution D (3\% NaCl at pH 2.41), 10 line scan Average $\mathrm{E}_{\mathrm{rpis}}--0.593 \mathrm{mV}, \quad \mathrm{E}_{\mathrm{eff}}-0.593 \mathrm{mV} ; \mathrm{CF}$ $134003.426824 \mathrm{mAcm}^{2} / \mathrm{V}$

The SVET test commenced with the performance of a PIS calibration using line scan rather than the conventional area scan. Probe peak output signal voltage values were averaged to reduce the error associated with inconsistent readings of probe signal. The PIS showed that for a particular solution, the signal increases with increasing $\mathrm{pH}$ values. This is principally due to the variation in the resistance posed by the positively and negatively charged ions as they move freely in solution.

\subsubsection{SS304 in 10\% $\mathrm{FeCl}_{3} .6 \mathrm{H}_{2} \mathrm{O}$ - SVET Test Versus SEM Images of Sample Surfaces \\ i. SVET Scan}

No visible pit formation was picked from the SVET equipment for 40 line-scans of SS304 from $0 \mathrm{~h}$ to $96 \mathrm{~h}$ immersion time in $10 \% \mathrm{FeCl}_{3} \cdot 6 \mathrm{H}_{2} \mathrm{O}$ as the line data showed mere straight lines.

\section{ii. SEM Micrographs}

At the end of the line scans carried out on the SS304 sample using SVET, no pit was picked up by the equipment, but the sample scanned using SEM revealed the formation of some pits along and outside the scribe as shown in Figure 9 and Figure 10.
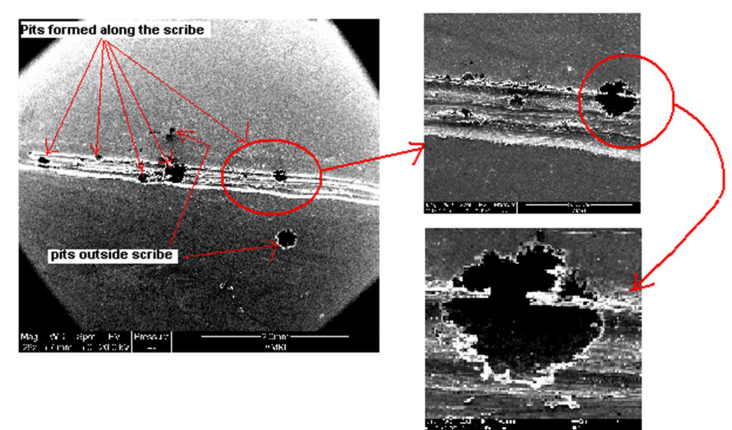

Figure 9. SEM Micrographs showing pits on SS304 sample after SVET line scan in $10 \% \mathrm{FeCl}_{3} .6 \mathrm{H}_{2} \mathrm{O}$ (SVET scan line 1). 

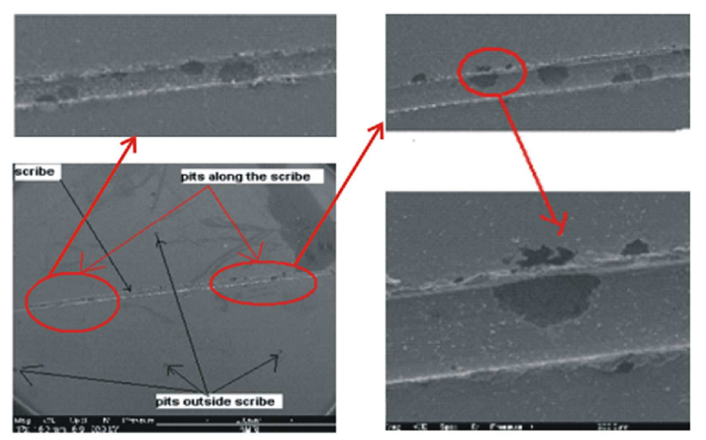

Figure 10. SEM Micrograph showing pits on SS304 sample after SVET line scan in $10 \% \mathrm{FeCl}_{3} .6 \mathrm{H}_{2} \mathrm{O}$ (SVET scan line 2).

Similarly, no pit was captured after area scans of the SS304 sample in $10 \% \mathrm{FeCl}_{3} \cdot 6 \mathrm{H}_{2} \mathrm{O}$ using SVET, but the sample scanned using SEM revealed the formation of some pits as shown in Figure 11.

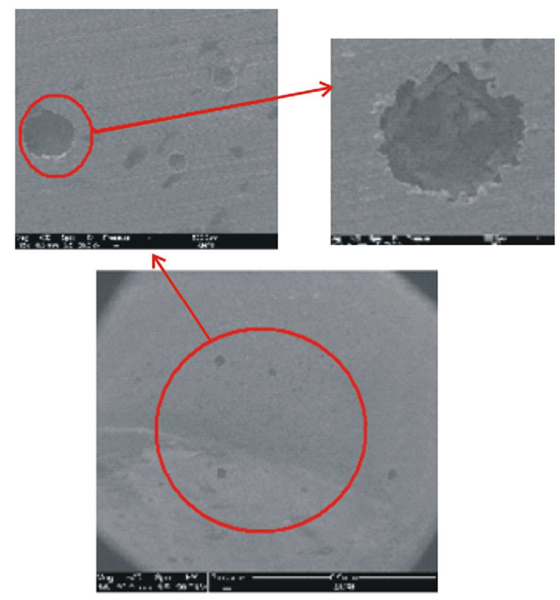

Figure 11. SEM Micrographs showing pits on SS304 surface after a SVET area scan in $10 \% \mathrm{FeCl}_{3} .6 \mathrm{H}_{2} \mathrm{O}$.

\subsection{3. $\mathrm{Al}$ in $3 \% \mathrm{NaCl}$}

\section{(i) SVET Scan}

The SVET was able to pick-up and map the pits as they form, grow and repassivate on $\mathrm{Al}$ sample in $3 \% \mathrm{NaCl}$ for $\mathrm{pH}$ 7.21 and $\mathrm{pH} 2.89$ (Figure 12). Only the first formations are shown.

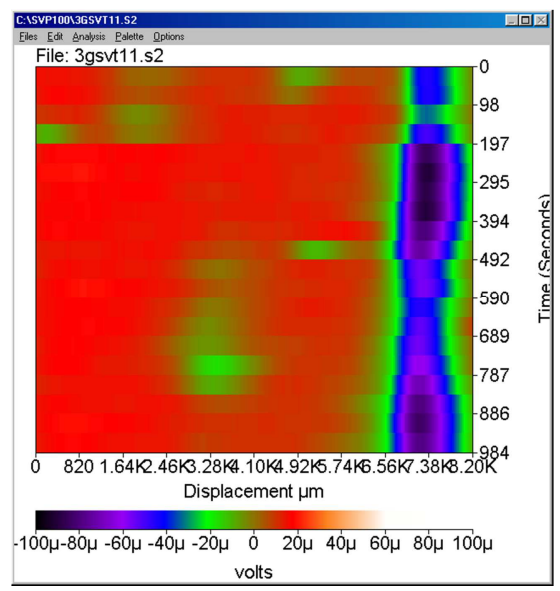

(a)

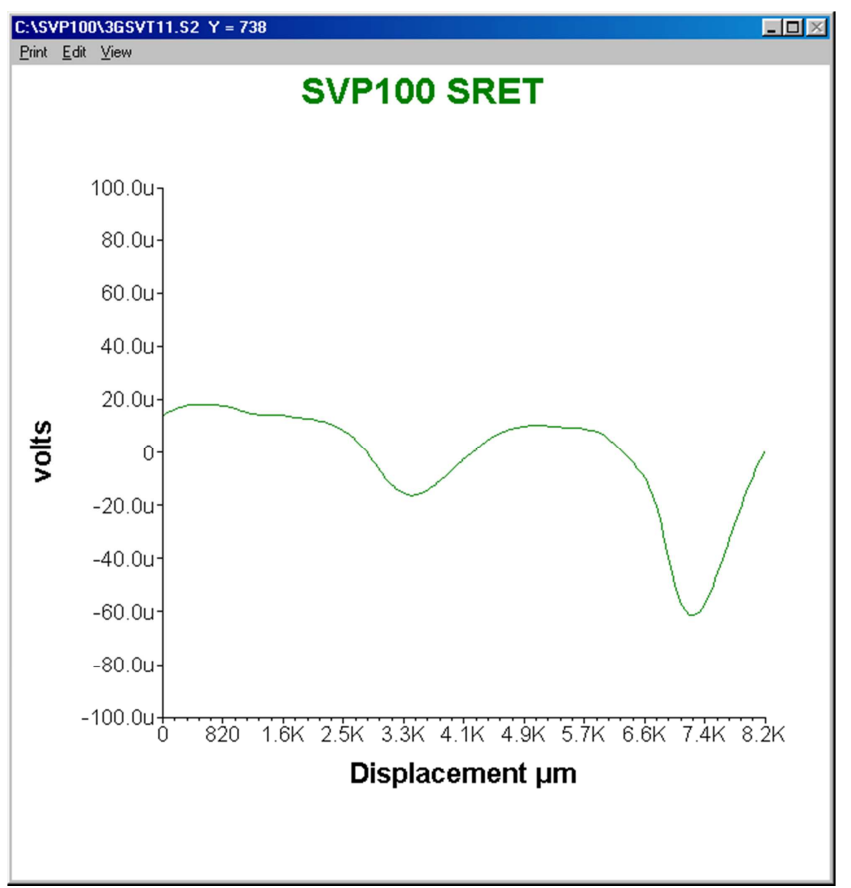

(b)

Figure 12. (a) Map showing 20 line scans for $\mathrm{Al}$ in $3 \% \mathrm{NaCl}$ at $\mathrm{pH} 2.89$ after $24 \mathrm{~h}$ immersion; (b) line data for line 16.

\section{(ii) SEM Micrographs}

At the end of the line and area scan carried out on the $\mathrm{Al}$ sample using SVET, the sample scanned using SEM revealed the formation of some pits as shown in Figure 13.

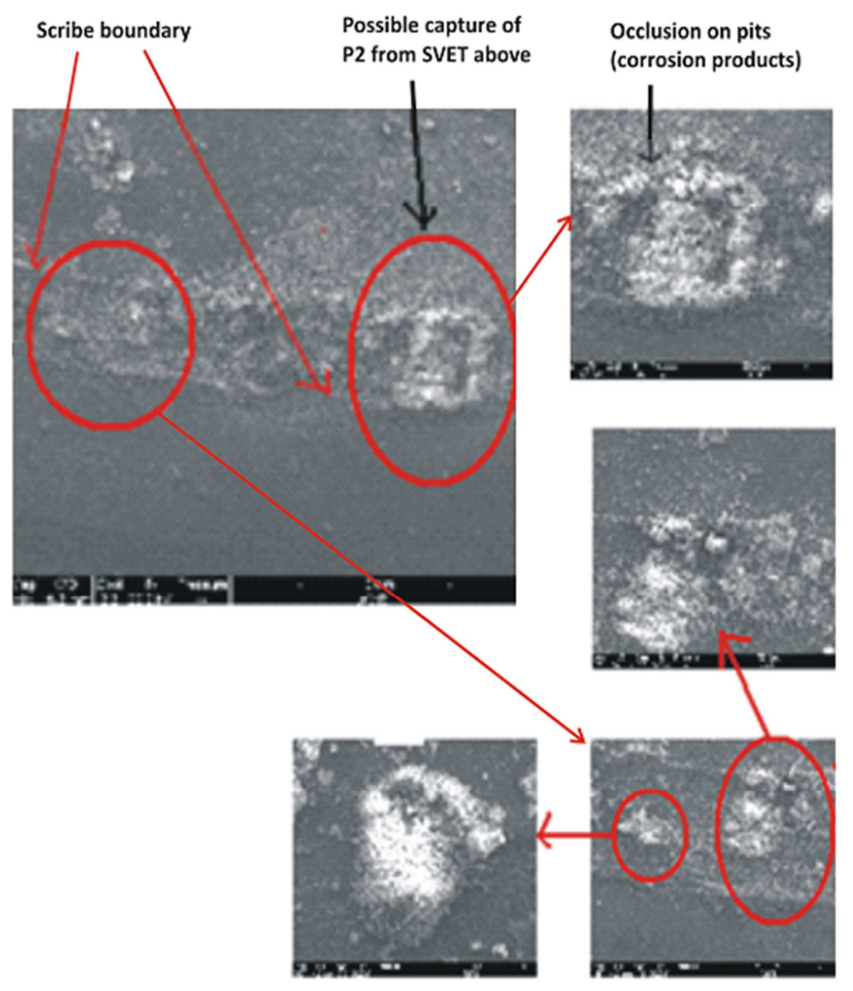

Figure 13. SEM image of $\mathrm{Al}$ in $3 \% \mathrm{NaCl}$ solution at $\mathrm{pH} 2.89$ showing distribution of corrosion products along scribe and possible occlusion of pits. 


\subsection{Computation of Corrosion Rate Due to Pitting}

Corrosion rates were calculated from equation (1) and plotted against time over the entire scanning and presented as Figure 14 for $\mathrm{Al}$ but that for SS304 is not presented because of the null values obtained.

$$
E_{\text {eff }}=\left|E_{\text {init }}-E_{\text {rpit }}\right|
$$

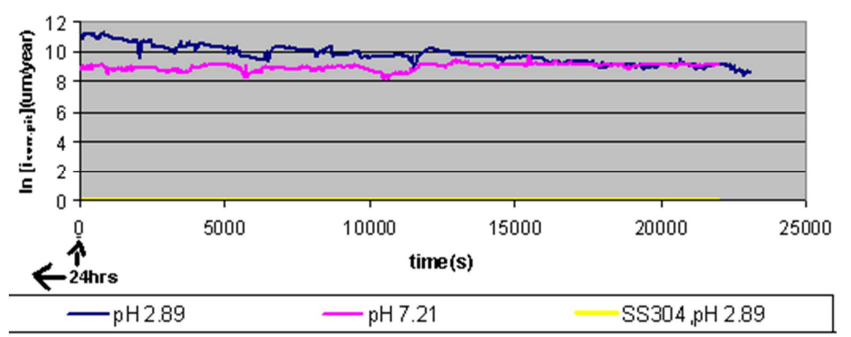

Figure 14. Corrosion rate Versus time for Al and SS304, in $3 \% \mathrm{NaCl}(\mathrm{pH}$ 2.89 and 7.21) using SVET after $24 \mathrm{~h}$ immersion).

The ability of a metal to pit in an environment has been regarded as a probabilistic issue [23]. It is then necessary to define the best probabilistic conditions upon which pitting may occur before any scanning. Scanning technique adopted is important because of the repassivation of pits which is also probabilistic in itself, picking up pits formation and growth before death. There is every tendency that probe gets to pit before formation or while pit is repassivated [24]. In an attempt to increase the chance of capturing a pit as they form, in the total immersion test it was found that the best surface profile for a sample being used in this kind of experiment is the one with a scribe on it, which is in line with the postulate of Pessall and Liu [25].

The ECN transients consist of uni and bi-directional transients, that is, anodic (positive) and cathodic (negative). Transients depict the nucleation, temporary growth and repassivation of small pits. Negative transients indicate the breakdown of passive films which are turned into active metal dissolution [26]. On observation of Figure 12, the cathodic current transients of SS304 reached values as small as $-3 \mathrm{e}^{-8} \mathrm{~mA} / \mathrm{cm}^{2}$ immediately after immersion, with also more spikes as compared with that after $24 \mathrm{~h}$ immersion, where a single transient of comparatively larger value of $-2.5 \mathrm{e}^{-}$ ${ }^{6} \mathrm{~mA} / \mathrm{cm}^{2}$ was obtained. This suggests that the SS304 pits with time in this solution as bigger transients are formed, that is larger metal dissolution. The current time record of $\mathrm{Al}$ (plot not included) showed numerous spikes indicating that the electrolyte is more corrosive to Al than SS304; although transients indicate pit formations but the randomness suggests that general kind of corrosion is more prominent than pitting. After $24 \mathrm{~h}$ immersion the record describes the same condition of corrosion activity although more general in this case than in the one encountered immediately after immersion as can be shown by the cluster of smaller transients.

A study using the $\mathrm{CoV}$, indicate that $\mathrm{SS} 304$ has a better pitting tendency than $\mathrm{Al}$ in $\mathrm{FeCl}_{3}$ solution, the steep slope observed in the value of the $\mathrm{CoV}$ for $\mathrm{Al} 6 \mathrm{~h}$ immersion could be as a result of general form of corrosion rather than pitting. This repeated after $48 \mathrm{~h}$; in essence $\mathrm{Al}$ suffers from severe general corrosion and pitting in $\mathrm{FeCl}_{3}$ solution unlike the SS304 with profile indicating gradual pitting process across the immersion period.

The test on SS304 in $\mathrm{pH} 2.89$ within the short period yielded no result with SVET. Also, microscope observation revealed no pits. This explains the resistance to natural pitting by SS304 in sea water condition and the inability for the $\mathrm{Cl}^{-}$present to break the passive film formed by the $\mathrm{Cr}$ element in the metal. However several tests performed on SS304, were able to get it to pit by the passage and withdrawal of an anodic current through the sample [24], [27]. On test with ferric chloride solution, SVET could not also pick and map any pits, but the SEM image in this instance revealed the formation of pits as in Figures 12, 13. The inability of SVET to pick and map these pits could be due to earlier arrival of probe at pitting site before formation or late arrival after pit repassivation.

Unlike the SVET scan on SS304, scan on pure Al in 3\% $\mathrm{NaCl}$ at $\mathrm{pH} 7.21$ and 2.89 , pits were correspondingly captured and mapped. We noticed that the early captured formations were more intense and gradually die away as the scan proceeds. The reason could be the possible repassivation of these pits or the subsequent closure of pits with or without the dynamic assistance of the probe tip as it scans past the pit, although some of the line scan data indicated pit growth in Figure 14. Another important factor to be considered is the probe waiting time before another line scan run over pit. The SEM image for the Al could only show the corrosion products as they are distributed over the surface, with heavier concentrations suspected to be around pit (s) mouth. The result of the computation done for $\mathrm{SS} 304$ and pure $\mathrm{Al}$, from the SVET maps suggest that pure $\mathrm{Al}$ is more prone to pitting attack than the SS304. It is also more severely attacked in $3 \% \mathrm{NaCl}$ solutions with lower $\mathrm{pH}$ values or more acidic as can be seen from the computed values of corrosion rate for line 16 which is assumed to have occurred at approximately the same time.

The single line or point analysis could possibly give a wrong indication of the susceptibility, hence a need for the overall study of the entire map over the time of run, will give a more representative result of the entire process and can be used as a better predictive model. The graph of Figure 14 developed for this study, apart from the instantaneous values of the pitting corrosion rate, gives us an overall profile of the formations. It suggest that the corrosion rate varied with over time. It is higher for pure $\mathrm{Al}$ in sea water of $\mathrm{pH} 2.89$ than that of neutral sea water. The gradual decline as seen from the graph could be as a result of the pits re-passivation, closure of pits by occluded corrosion products by the probe while scanning or mass transport of the electrolyte during activity. It should be noted that the plot of SS304 showed no variation as no sudden voltage drops indicative of pitting being recorded by the SVET.

Importantly, the use of effective value of sudden voltage 
drops, is necessitated by the fact that we are only considering the transients formed as a result of pitting activity (cathodic or anodic), the SVET setting could give an initial non zero reading $\left(\mathrm{E}_{\text {init }}\right)$ which signifies a false corrosion activity where there is none. The value of voltage drop caused by the sudden anodic dissolution is the steep voltage produced which is termed the effective voltage $\left(\mathrm{E}_{\text {eff }}\right)$ in this work. This has the property of singling or extracting out the corrosion due to pitting alone, void of other perturbations.

\section{Conclusion}

- In-situ evaluation of pitting corrosion by ECN and SVET increases the chance of capturing pits formation, growth and repassivation in the corrosion experiments.

- Line scans along a scribe has a greater chance of capturing pits formation more than area scan. Also, the use of reduced electrolyte basin enhanced measurements better flexibility; in terms of the electrolytes, number of requisite experimental runs and probe proximity to the activity sites. Crevice attacks at interfaces could not be eliminated completely; necessitating the covering of interfaces with colophony resin beeswax to reduce crevice attack on sample before immersion into electrolyte.

- The coefficient of variation $(\mathrm{CoV})$ can be used as a screen (sorting) test for pitting susceptibility preparatory to SVET test. The consistence of pitting with respect to $\mathrm{CoV}$ was noticed for $\mathrm{pH}$ value around 3.09/2.35 after $24 \mathrm{~h}$ immersion.

- SVET has proven a veritable technique for capturing pitting and pitting-susceptibility for Al though it could not capture the pit formation in SS304. This is attributable to (a) inappropriate and inadequate experimental controls of the system electrochemistry, (b) short time of pit formations and repassivation compared to the experiment time.

- Gas formation and heavy deposit of corrosion product reveals a high overall continuous corrosion reaction in $\mathrm{Al}$. This intense dynamic environment could be a facilitator for the proper functionality of the SVET equipment.

- The signal output of the SVET over a period of time could be used as a measure of susceptibility of a metal to pitting corrosion in a particular environment. It has been shown that $\mathrm{Al}$ is prone to heavier pitting in a more acidic environment, and the $\mathrm{pH}$ of a corrosive environment drives the pitting susceptibilities of the metals exposed in that environment.

- SVET maps for Al with their corresponding sudden voltage drops, corrosion rate values computed can be used to study the mechanism of $\mathrm{H}_{2}$ evolution in the pitting process - reduction in pitting corrosion rate denotes reduction in anodic dissolution hence $\mathrm{H}_{2}$ evolution.

- The effective voltage drop was able to quantify the dissolution associated with only the pitting action rather than a combination of all the parameters that contribute to potential drop.

- Absolute values of transients rather than the number of transients explain better pitting susceptibility.

- ECN and SVET have the capability of capturing and mapping pits in time domains but the former does not give geometric position of pit formation. ECN has a greater chance of capturing pits than SVET but lacks proper quantification of the pits.

- SS304 pits more than $\mathrm{Al}$ in $\mathrm{FeCl}_{3}$, with $\mathrm{Al}$ exhibiting general / uniform corrosion attack.

- Pit formation in SS304 is more difficult to capture than that of Al. Al pits more than SS304 in salt water, where its pitting susceptibility is more in an acidic medium compared to that of a neutral medium.

\section{Acknowledgement}

Scholars extend appreciation to Mr. Peter Forshaw of Uniscan for ensuring the effective operation of the SVET equipment. The management of the Advanced Material Research Institute (AMRI), Northumbria University Newcastle-Upon-Tyne is highly appreciated for the privilege of using her research infrastructures in this study.

\section{References}

[1] Rogers, H. T., "Marine Corrosion", George Newnes ltd, London, 1968.

[2] Atkins P. W., "Analytical Chemistry" $3^{\text {rd }}$ Ed., (Oxford University Press: Oxford, 1986).

[3] Trethewey, K. R. and Chamberlain J. "Corrosion for Science and Engineering" $2^{\text {nd }}$ Ed. (Longman: England,1995)

[4] Fontana, M. G., "Corrosion Engineering", $3^{\text {rd }}$ Ed., (McGraw-Hill book company: Singapore, 1987).

[5] Sedriks J. A., "Corrosion of Stainless Steels" (John Wiley and Sons: New York, 1979).

[6] Jones K., Hoeppner D. W., Pit to Crack Transition in Precorroded 7075-T6 Aluminium alloy under cyclic loading" Corrosion science, 2004, article in press.

[7] Ladislav Kavan, Zuzana Vlckova Zivcova, Vaclav Petrak, Otakar Frank, Pavel Janda, Hana Tarabkova, Milos Nesladek, Vincent Mortet; "Boron-doped Diamond Electrodes: Electrochemical, Atomic Force Microscopy and Raman Study towards Corrosion-modifications at Nanoscale", Electrochimica Acta, Volume 179, 10 October 2015, Pages 626-636.

[8] Renate Hiesgen, Stefan Helmly, Tobias Morawietz, Xiao-Zi Yuan, Haijiang Wang, K. Andreas Friedrich; "Atomic force microscopy studies of conductive nanostructures in solid polymer electrolytes", Electrochimica Acta, Volume 110, 1 November 2013, Pages 292-305.

[9] J. Izquierdo, B. M. Fernández-Pérez, A. Eifert, R. M. Souto, C. Kranz; "Simultaneous Atomic Force-Scanning Electrochemical Microscopy (AFM-SECM) Imaging Of Copper Dissolution", Electrochimica Acta, In Press, Corrected Proof, Available online 29 December 2015. 
[10] Timo Carstens, Adriana Ispas, Natalia Borisenko, Rob Atkin, Andreas Bund, Frank Endres; "In situ scanning tunneling microscopy (STM), atomic force microscopy (AFM) and quartz crystal microbalance (EQCM) studies of the electrochemical deposition of tantalum in two different ionic liquids with the 1-butyl-1-methylpyrrolidinium cation", Electrochimica Acta, Volume 197, 10 April 2016, Pages 374387.

[11] Emerson C. Rios, Alexsandro M. Zimer, Ernesto C. Pereira, Lucia H. Mascaro; Analysis of AISI 1020 steel corrosion in seawater by coupling electrochemical noise and optical microscopy", Electrochimica Acta, Volume 124, 1 April 2014, Pages 211-217.

[12] Fernanda Hass, Ana C. T. G. Abrantes, Alysson N. Diógenes, Haroldo A. Ponte; "Evaluation of naphthenic acidity number and temperature on the corrosion behavior of stainless steels by using Electrochemical Noise technique", Electrochimica Acta, Volume 124, 1 April 2014, Pages 206-210.

[13] T. Balusamy, T. Nishimura; "In-Situ Monitoring of Local Corrosion Process of Scratched Epoxy Coated Carbon Steel in Simulated Pore Solution Containing Varying percentage of Chloride ions by Localized Electrochemical Impedance Spectroscopy", Electrochimica Acta, Volume 199, 1 May 2016, Pages 305-313.

[14] M. Curioni, F. Scenini, T. Monetta, F. Bellucci; "Correlation between electrochemical impedance measurements and corrosion rate of magnesium investigated by real-time hydrogen measurement and optical imaging", Electrochimica Acta, Volume 166, 1 June 2015, Pages 372384 .

[15] Hui Xu, Yu Liu, Wen Chen, Rong-Gui Du, Chang-Jian Lin; "Corrosion behavior of reinforcing steel in simulated concrete pore solutions: A scanning micro-reference electrode study", Electrochimica Acta, Volume 54, Issue 16, 30 June 2009, Pages 4067-4072.

[16] J. Izquierdo, B. M. Fernández-Pérez, L. Martín-Ruíz, V. Mena, R. Rodríguez-Raposo, J. J. Santana, R. M. Souto "Evaluation of the corrosion protection of steel by anodic processing in metasilicate solution using the scanning vibrating electrode technique," Electrochimica Acta, Volume 178, 1 October 2015, Pages 1-10.
[17] Sara M. Manhabosco, Álvaro Pritzel dos Santos, Marcelo L. Marcolin, Eurico F. Pieretti, Mauricio D. M. Neves, Luís F. P. Dick; "Localized corrosion of laser marked M340 martensitic stainless steel for biomedical applications studied by the scanning vibrating electrode technique under polarization," Electrochimica Acta, Volume 200, 10 May 2016, Pages 189-196.

[18] Roberts C., Stephen T., B. C. Syrett (Ed), "Electrochemical Impedance and Noise" (NACE International: Houston, USA, 1999).

[19] Volkov A. O., Datta P. K., Burnell-Gray, J. S., Couper R., "Hydrodynamic Measurement of a Single Corrosion Pit Corrosion Science, 2004, 46, pp. 2613-2619.

[20] Uniscan Instrument SRE ${ }^{\mathrm{TM}}$ Model SVP100 "Scanning Vibrating Electrochemical Probe System Operations Manual, Version 1, PP. 27.

[21] Betts, J. A. (1974); "Signal Processing, Modulation and Noise," Hodder and Stoughton Publishers, PP. 79.

[22] Cappeln F. V., Bjerrum N. J., Petrushina I. (2005); "Electrochemical Noise Measurement of Steel Corrosion in the molten NaCl- $\mathrm{K}_{2} \mathrm{SO}_{4}$ System; J. of Electrochemical Society, Vol. 152 (7), B228 - B235, 10.1149/1.1928187.

[23] Mears R. B. and Evans U. R., Trans Faraday soc. 31, 527 (1935).

[24] Haitem A., "Investigation into Hydrodynamics of Pitting Corrosion on Stainless Steel" MSc. Thesis, School of Engineering and Technology, Northumbria University, 2005.

[25] Pessall N., Liu C. (1971) Electrochimica. Acta. 16 (11) PP. $1987-2003$.

[26] Acuna N., "Fatigue Corrosion Cracking of an austenitic Stainless Steel using Electrochemical Noise Technique.", Journal of Anti Corrosion Methods and Materials, Vol. 52/3 (2005), pp. 139-144.

[27] Wipf D., "Initiation and Study of Localised Corrosion by Scanning Electrochemical Microscopy" Journal of Colloids and Surfaces: A Physicochemical and Engineering aspects, 1994, 93, pp. 251-261. 